\title{
CAPÍTULO 10: CARACTERÍSTICAS TECNOLÓGICAS E SENSORIAIS DE HAMBÚRGUERES ELABORADOS COM FARINHA DE AVEIA COMO SUBSTITUTO PARCIAL DE GORDURA
}

\section{CHAPTER 10: TECHNOLOGICAL AND SENSORY CHARACTERISTICS OF HAMBURGERS PREPARED WITH OAT FLOUR AS PARTIAL FAT SUBSTITUTE}

\author{
Magda Maria Oliveira Inô ${ }^{1}$; Adriana Mendes Oliveira ${ }^{2}$; Vanessa Regina Kunz ${ }^{3}$ Luiz Fernando Souza \\ Almeida ${ }^{4}$; Ítalo Abreu Lima ${ }^{5}$
}

\begin{abstract}
Resumo
Os consumidores, em busca de alimentação saudável, exigem do mercado produtos com melhor qualidade e oferta regular. Devido a essa necessidade, buscou-se elaborar um produto cárneo acrescido de fibras, realizar a análise sensorial, microbiológica e físicoquímicas. Foram elaboradas 4 formulações de hambúrgueres bovinos (T1: 0,0\% farinha de aveia e 17,4\% de gordura); (T2: 4,4\% farinha de aveia e 13,0\% gordura); (T3: 8,7\% farinha de aveia e 8,7\% gordura) e T4 (13,0\% farinha de aveia e 4,4\% gordura). A adição de farinha de aveia não influenciou os teores de umidade dos produtos elaborados $(P>$ $0,05)$, que ficou entre 59 e $61,87 \%$. Para os demais parâmetros houve efeito significativo entre os tratamentos $(P<0,05)$. Em relação aos lipídeos, todos os tratamentos atenderam a Legislação Brasileira. Os valores de $\mathrm{pH}$ e atividade de água aumentaram à medida que reduziu a gordura. $\mathrm{Na}$ análise sensorial não foi detectado diferença significa $(p>0,05)$ entre os tratamentos para os atributos sabor e aroma. A substituição do toucinho pela farinha de aveia não só resultou em um produto de menor valor calórico, mas também melhorou características tecnológicas de rendimento, encolhimento e perda de peso, além de uma boa aceitação sensorial.
\end{abstract}

Palavras-Chaves: Produto reestruturado, Fibra, Alimento Funcional.

\begin{abstract}
Consumers, in search of healthy food, demand from the market products with better quality and regular supply. Due to this need, we sought to develop a meat product with added fibers, to carry out sensory, microbiological and physical-chemical analysis. 4 formulations of beef hamburgers were prepared (T1: $0.0 \%$ oatmeal and $17.4 \%$ fat); (T2: $4.4 \%$ oatmeal and $13.0 \%$ fat); (T3: $8.7 \%$ oatmeal and $8.7 \%$ fat) and T4 (13.0\% oatmeal and $4.4 \%$ fat). The addition of oatmeal did not influence the moisture content of the elaborated products $(\mathrm{P}>0.05)$, which was between 59 and $61.87 \%$. For the other parameters, there was a significant effect between treatments $(\mathrm{P}<0.05)$. Regarding lipids, all treatments complied with Brazilian legislation. The $\mathrm{pH}$ and water activity values increased as fat decreased. In the sensory analysis, no significant difference ( $p>0.05)$ was detected between treatments for the flavor and aroma attributes. The replacement of bacon by oatmeal not only resulted in a product with lower caloric value, but also improved technological characteristics of yield, shrinkage and weight loss, in addition to good sensory acceptance.
\end{abstract}

\footnotetext{
${ }^{1}$ Engenharia de Alimentos, IFBA/Campus Barreiras, m.oliveira.ino@gmail.com

${ }^{2}$ Engenharia de Alimentos, IFBA/Campus Barreiras, adrianamendes_oliveira@hotmail.com

${ }^{3}$ Engenharia de Alimentos, IFBA/Campus Barreiras, va-nessak@ hotmail.com

${ }^{4}$ Engenharia de Alimentos, IFBA/Campus Barreiras, luizfernando@ifba.edu.br

${ }^{5}$ Doutorado, IFBA/Campus Barreiras, italoabreu@ifba.edu.br
} 
Keywords: Restructured product, Oats, Functional food, Fiber.

\section{Introdução}

A Legislação (BRASIL, 2000) define como hambúrguer "produto cárneo industrializado, obtido de carne moída dos animais de açougue, adicionado ou não de tecido adiposo e ingredientes, moldado e submetido a processo tecnológico adequado". Trata-se de produto cru, semifrito, cozido, frito, congelado ou resfriado', conforme a sua classificação.

O hambúrguer tem como ingrediente obrigatório carne de diferentes espécies de animais de açougue e como ingredientes opcionais gordura (animal ou vegetal), água, sal, proteínas (animal e/ou vegetal), leite em pó, açúcares, malto-dextrina, aditivos intencionais, condimentos, aromas e especiarias, vegetais, queijos e outros recheios. Apresenta como parâmetros físico-químicos de acordo com o Regulamento Técnico de Identidade e Qualidade, os teores de lipídios no máximo 23,0 \%, proteína mínimo de 15,0 $\%$, carboidratos totais máximo de $3,0 \%$ e o teor de cálcio (máximo em base seca) $0,1 \%$ no hambúrguer cru e 0,45 \% no hambúrguer cozido (BRASIL, 2000).

Atualmente, é cada vez mais evidente a busca por produtos de preparo rápido, em virtude do ritmo urbano, dado pelo tempo produtivista do processo de produção, que acaba invadindo a vida social e impondo aos cidadãos, principalmente das grandes cidades, alguns comportamentos de consumo, dados pela escassez do tempo (TREVISAN et al., 2016; JUNIOR, 2017; PAULA, et al., 2019).

Entre os produtos cárneos mais apreciados mundialmente temos o hambúrguer, que devido a facilidade de preparo, se tornou um produto consumido por todas as classes sociais. Esse produto é fabricado a partir da carne moída, com adição ou não de gordura e condimentos, sendo posteriormente moldado. Quando adicionado de substâncias prebióticas como as fibras, desempenham funções benéficas ao organismo além de nutrir, sacia a fome rapidamente, o que combina com o atual modo de vida dos habitantes dos centros urbanos (OLIVEIRA et al., 2014; SILVA et al., 2018).

A adição de fibras alimentares na alimentação humana, especialmente em produtos cárneos proporciona um melhor rendimento no cozimento, aumenta a capacidade de retenção de água, reduz o custo da formulação e agrega características funcionais ao alimento (PAULA, et al., 2019).

Segundo Colmenero (2001), produtos cárneos convencionais do tipo fast food possuem alto conteúdo de gordura, variando entre 20 e $30 \%$.Vários experimentos sobre 
INÔ, et al.

o uso de substitutos de gorduras em produtos cárneos, especialmente em hambúrguer, vêm sendo desenvolvidos, uma vez que, embora consumido por todas as classes populares em virtude da praticidade que representa e por possuir nutrientes que alimentam e saciam a fome rapidamente (JUNIOR, 2017; BIS, 2016; GONÇÁLVES, et al., 2016; CARVALHO, 2015; VALENTE, et al., 2014; DA SILVA et al., 2014), o consumo demasiado desse tipo de produto pode ser prejudicial à saúde humana, causando obesidade e doenças, como hipertensão, diabetes mellitus e dislipidemias.

A adição de gordura na formulação de produtos cárneos é utilizada para se obter suculência e maciez. Embora a gordura seja necessária para várias funções do organismo humano, e ser utilizada nas formulações de produtos cárneos para garantir textura macia e sabor, quantidades elevadas podem trazer riscos à saúde e aumentar o risco de doenças (JUNIOR, 2017; GONÇÁLVES, et al., 2016).

Dos produtos cárneos industrializados, nos quais tem sido estudada a influência da adição de fibras na diminuição do teor de gordura dos mesmos, o hambúrguer tem recebido merecida atenção. Dentre as fibras recentemente utilizadas como ingredientes em alimentos cárneos industrializados, as adições de carragena, fibra solúvel de aveia ( $\beta$ glucana), farelo de aveia, fécula de mandioca, fibra de soja, fibra de ervilha, goma, farelo de linhaça, farinha de gergelim, farinha de quinoa, farinha da casca de abacaxi, fibra de aveia e semente de chia (ANDERSON e BERRY, 2001; SEABRA et al., 2002; QUEIROZ et al., 2005; MARQUES, 2007; PIÑERO et al., 2008; MONEGO, 2009; CIRIANO et al., 2013; Melo et al., 2013; MACHADO, 2014; LÓPEZ-VARGAS et al., 2014; TREVISAN et al., 2016; JUNIOR, 2017; PAULA, et al., 2019) foram ressaltadas como alternativas para um produto mais saudável.

Outro tipo de fibra utilizado como substituto de gordura é a de aveia. Muitas das características da fibra de aveia, como a alta capacidade de absorção de água, inclusive durante o cozimento, por dar a sensação bucal similar a gordura, pela ausência de sabor de cereais e porque contribui com fibra dietética nos produtos, poderiam potencialmente beneficiar produtos como hambúrguer (TREVISAN et al., 2016).

Produtos de aveia também têm uma imagem positiva com o consumidor, porque alguns benefícios a saúde estão relacionados ao consumo de produtos de aveia, como o uso de fibra alimentar da aveia e a diminuição do colesterol sérico (CARBONELL et al., 2005).

Diante disto, a redução do teor de gordura e a adição de ingredientes funcionais em produtos cárneos reestruturados como hambúrgueres apresentam-se como tendências 
no desenvolvimento de produtos na indústria de carnes (JUNIOR, 2017). No entanto, no Brasil, ainda não existem opções comerciais de produtos cárneos reestruturados com adição de fibras vegetais para consumo em geral, podendo tornar os resultados deste estudo um referencial de interesse para as indústrias frigoríficas.

Sendo assim, esse trabalho teve como objetivo desenvolver e caracterizar através de análises físico-química e sensorial, hambúrgueres de carne bovina com adição de farinha de aveia, em substituição parcial da gordura suína.

\section{Material e Métodos}

O presente estudo foi realizado nos Laboratórios de Tecnologia de Carnes e Derivados; de Análise de Alimentos e de Microbiologia de Alimentos do Instituto Federal da Bahia (IFBA), Campus Barreiras. Foram utilizadas carne de dianteiro bovino (acém) e gordura suína (toucinho), obtidas de estabelecimentos comerciais na cidade de Barreiras - BA. Em seguida foram transportadas ao Laboratório de Carnes e Derivados do IFBA, Campus Barreiras onde foram mantidos congelados até sua utilização. A farinha de aveia e a proteína texturizada de soja também foram adquiridas em estabelecimentos comercial de Barreiras-BA.

O processamento dos produtos foi baseado conforme descrito por Terra (1998), sendo, no entanto, realizado algumas adaptações. As peças cárneas foram limpas, o que constitui na separação de pedaços cárneos sem tamanho determinado, com consequente remoção do excesso de gorduras, nervos, aponeuroses e hematomas presentes. Em seguida, moídas em disco de $8 \mathrm{~mm}$ e o toucinho moído em disco de $5 \mathrm{~mm}$.

A mistura dos hambúrgueres foi realizada manualmente em caixas plásticas, adicionando-se as quantidades definidas de carne moída, gordura, PTS (proteína de soja) previamente hidratada, água gelada, condimento global para hambúrguer (empresa Ibrac) e farinha de aveia, lentamente, até a formação de uma mistura homogênea. Foram obtidas quatro formulações, conforme observada na Tabela 01.

Tabela 01. Formulação básica para elaboração de Hambúrgueres.

\begin{tabular}{lccccc}
\hline \multirow{2}{*}{ Matéria-prima (Massa) } & \multicolumn{4}{c}{ Formulações (\%) } \\
\cline { 2 - 6 } & T1 & T2 & T3 & T4 \\
\hline \hline Acém bovino & 65 & 65 & 65 & 65 \\
Gordura suína & 17,4 & 13 & 8,7 & 4,4 \\
Farinha de aveia & 0 & 4,4 & 8,7 & 13 \\
Água gelada & 4,4 & 4,4 & 4,4 & 4,4 \\
Proteína texturizada de soja (PTS) & 4,4 & 4,4 & 4,4 & 4,4
\end{tabular}


INÔ, et al.

\begin{tabular}{|c|c|c|c|c|}
\hline Água para hidratar a PTS & 8,8 & 8,8 & 8,8 & 8,8 \\
\hline Total & 100 & 100 & 100 & 100 \\
\hline
\end{tabular}

\begin{tabular}{clllll}
\hline \hline Condimento global (Mix) para Hambúrguer & 4 & 4 & 4 & 4 \\
\hline Fon
\end{tabular}

Fonte: Própria (2020).

Após a homogeneização dos ingredientes de cada formulação, os hambúrgueres foram prensados e moldados com hamburgueira manual de $11 \mathrm{~cm}$ de diâmetro, obtendose hambúrgueres com peso líquido de $80 \mathrm{~g}$ cada, embalados em sacos de polietileno e congelados em freezer a $-18{ }^{\circ} \mathrm{C}$ até o momento das análises.

Foi avaliada a perda de peso no forno micro-ondas (PPMO) dos hambúrgueres, em triplicata, durante o aquecimento por dois minutos (tempo necessário para que as amostras congeladas atingissem temperatura de $75{ }^{\circ} \mathrm{C}$ no seu centro geométrico), conforme TREVISAN et al., 2016.

O rendimento foi calculado em triplicata, de acordo com a Equação 1, e a porcentagem de encolhimento dos hambúrgueres em triplicata, com base na variação do diâmetro do produto cru e cozido, de acordo conforme a Equação 2 (MARQUES, 2007):

Equação 01: \% rendimento $=\frac{\text { Peso da amostra cozida } \times 100}{\text { Peso da amostra crua }}$

Equação 02: \% encolhimento =

(Diâmetro da amostra crua - Diâmetro da amostra cozida) x 100

Diâmetro da amostra crua

A umidade foi determinada por secagem em estufa a $105^{\circ} \mathrm{C}$ e o extrato etéreo, pelo método de Soxhlet, segundo metodologias oficiais da Associação Oficial de Análises Químicas (AOAC, 2002). Essas análises foram feitas em triplicata.

A atividade de água (aw) dos produtos acabados foi determinada por meio de um aparelho Aqualab digital modelo série 3TE da Decagon Devices, EUA (DECAGON DEVICES Inc, 2003). O pH foi medido por potenciometria (Peagâmetro Orion, modelo 710 A) de acordo com o método (TERRA; BRUM, 1988). Todas as determinações foram feitas em triplicata.

A avaliação microbiológica dos produtos prontos para o consumo foi realizada após estocagem sob congelamento. Foram feitas análises microbiológicas de contagens de coliformes a $45^{\circ} \mathrm{C}$ segundo a metodologia de Silva, Junqueira e Silveira (2001).

As análises microbiológicas de coliformes a $45^{\circ} \mathrm{C}$ foram realizadas pela técnica 
do Número Mais Provável (NMP), utilizando-se caldo Lauril Sulfato Triptose (LST) para o teste presuntivo e Caldo Verde Brilhante (CVB) para confirmar coliformes a $30^{\circ} \mathrm{C}$ e caldo EC para confirmar a fermentação a $45^{\circ} \mathrm{C}$. O resultado foi expresso em NMP por grama.

A análise sensorial foi realizada após aprovação do Comitê de Ética em Pesquisa do IFBA, sob o protocolo CAAE 06758817.6.0000.5031, conforme Resolução no 196/96, do Conselho Nacional de Saúde, tendo os participantes assinado um Termo de Consentimento Livre e Esclarecido (TCLE).

Para a aferição da análise sensorial foi aplicado um teste de perfil de consumo e um teste de aceitação com atributos cor, sabor, textura, aroma e aparência, em uma escala hedônica de 9 pontos, cujos extremos ancoram nos termos "1 - desgostei muitíssimo" e “9 - gostei muitíssimo", de acordo com a Figura 01. As amostras foram analisadas por uma equipe de 30 provadores não treinados, compostos por alunos e funcionários do IFBA, campus Barreiras. Cada julgador recebeu uma amostra de cada tratamento (aproximadamente $20 \mathrm{~g}$ ), totalizando 4 amostras de hambúrguer.

Figura 01. Ficha de avaliação sensorial e perfil de consumo de hambúrguer.

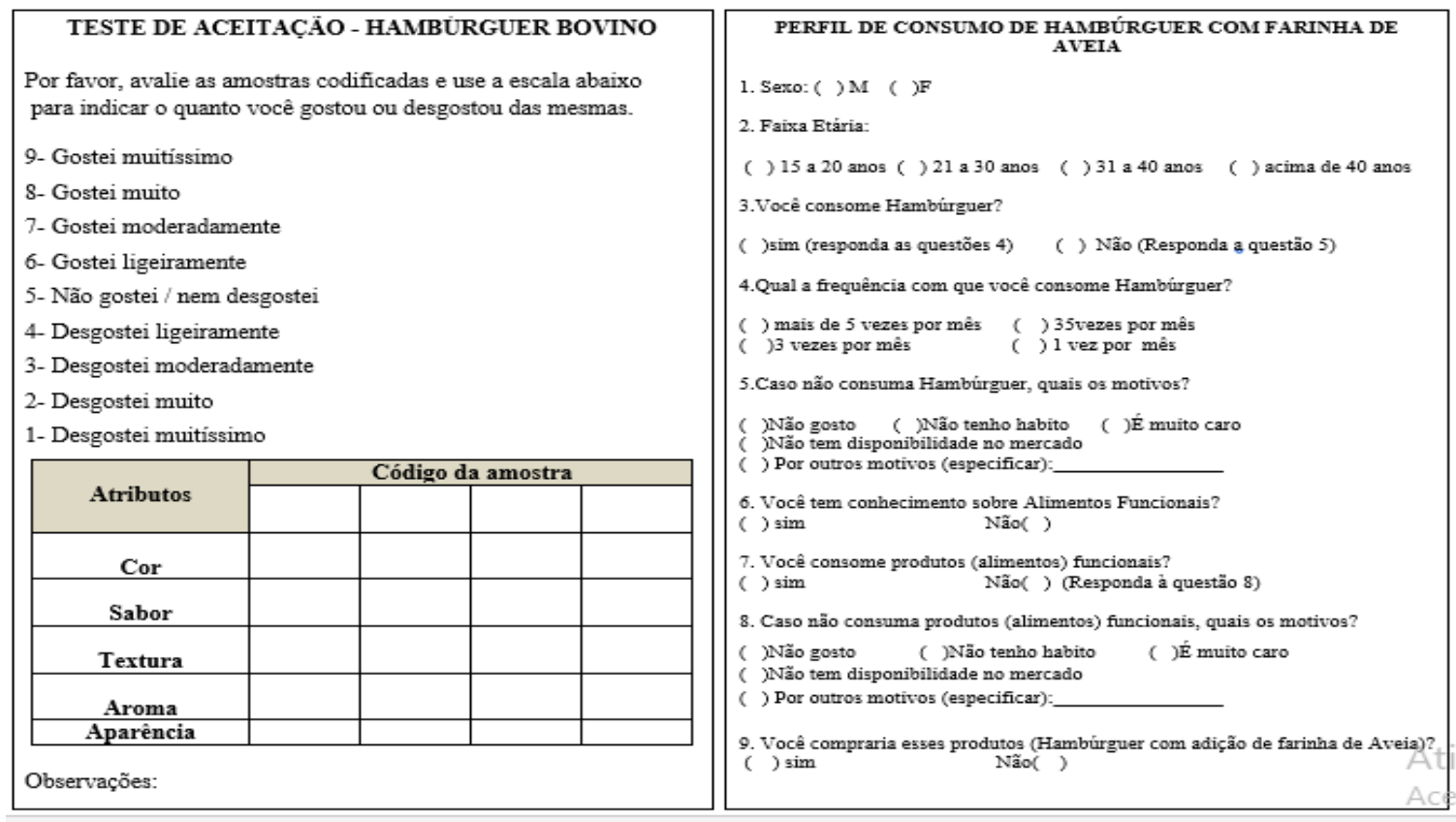

Fonte: Própria (2020).

Os hambúrgueres foram submetidos à cocção em grelha elétrica. A cada 1 minuto, foram virados, até apresentar aspecto de grelhado. O tempo de grelha foi em média de 9 minutos, até temperatura interna de $71^{\circ} \mathrm{C}$ por 15 segundos (ARISSETO e POLLONIO, 2005). As amostras foram envolvidas em papel alumínio e mantidas em estufa, numa 
INÔ, et al.

temperatura de $60^{\circ} \mathrm{C}$, até o momento de servir aos julgadores (15 min) para avaliação sensorial.

\section{Resultados e Discussão}

Os resultados dos parâmetros de umidade, lipídios, pH e atividade de água (Aw) dos hambúrgueres elaborados com farinha de aveia em substituição parcial da gordura estão representados na Tabela 02.

De acordo com os dados apresentados na Tabela 02, percebe-se que adição de farinha de aveia não influenciou os teores de umidade dos produtos elaborados, visto que não houve diferença significativa $(P>0,05)$ entre os tratamentos.

Tabela 02. Média ( \pm desvio padrão) dos parâmetros físico-químicos dos hambúrgueres.

\begin{tabular}{ccccc}
\hline \multirow{2}{*}{ Tratamentos } & \multicolumn{4}{c}{ Parâmetros Físico-químicos } \\
\cline { 2 - 5 } & Umidade (\%) & Gordura (\%) & pH & Atividade de Água (Aw) \\
\hline \hline T1 & $59,27 \pm 1,23^{\mathrm{a}}$ & $23,0 \pm 0,69^{\mathrm{a}}$ & $5,86 \pm 1,36^{\mathrm{a}}$ & $0,959 \pm 0,01^{\mathrm{a}}$ \\
T2 & $60,3 \pm 1,01^{\mathrm{a}}$ & $18,4 \pm 0,74^{\mathrm{b}}$ & $5,86 \pm 1,33^{\mathrm{a}}$ & $0,968 \pm 0,00^{\mathrm{b}}$ \\
T3 & $61,87 \pm 1,40^{\mathrm{a}}$ & $16 \pm 0,81^{\mathrm{c}}$ & $5,91 \pm 1,37^{\mathrm{b}}$ & $0,975 \pm 0,01^{\mathrm{c}}$ \\
T4 & $59,0 \pm 0,39^{\mathrm{a}}$ & $12 \pm 0,67^{\mathrm{d}}$ & $5,9 \pm 1,37^{\mathrm{b}}$ & $0,974 \pm 0,01^{\mathrm{c}}$ \\
\hline
\end{tabular}

T1(0,0\% farinha de aveia, 17,4\% de gordura suína); T2 (4,4\% farinha de aveia, 13,0\% gordura suína); T3(8,7\% farinha de aveia, 8,7\% gordura suína) e T4 (13,0\% farinha de aveia, 4,4\% gordura suína). Médias seguidas de letras diferentes na mesma coluna diferem $(\mathrm{p}<0,05)$ entre si pelo teste $\mathrm{F}$.

Fonte: Própria (2020).

Este resultado pode indicar que a emulsão cárnea formada foi estabilizada pela ação eficiente das proteínas miofibrilares, mantendo o teor de água na matriz, o que pode implicar na suculência do hambúrguer. A umidade se constitui em um parâmetro importante para a suculência e palatabilidade de produtos cárneos (BORBA et al., 2013).

No presente trabalho, a média dos tratamentos para umidade foi de $60,11 \%$, bem próximo ao encontrado por Trevisan et al., (2016), que avaliaram a adição de fibra de aveia (3 e 6\%) sobre as propriedades físico-químicas de hambúrgueres. Este comportamento não foi percebido por MARQUES (2007), o qual estudou formulações de hambúrgueres adicionados de diferentes concentrações de farinha de aveia e cuja umidade diminuiu com o aumento da concentração de farinha.

Em relação à quantidade de lipídeos, a adição de farinha de aveia teve efeito significativo $(P<0,05)$. Todos os tratamentos estavam de acordo com valores estabelecidos pela Legislação Brasileira (BRASIL, 2000), que determina teores máximos de $23 \%$ de gordura em hambúrgueres. A gordura é um ingrediente importante aplicado nas formulações de produtos alimentícios, pois contribuí para melhor palatabilidade, 
maciez e suculência (JIMÉNEZ-COLMENERO, 2007).

Os hambúrgueres adicionados de farinha de aveia nas proporções de: 8,7\% (Tratamento 3) e 13\% (Tratamento 4), apresentaram uma redução importante do teor de lipídeos, da ordem de $30 \%$ e $47 \%$ respectivamente, quando comparado ao tratamento controle (Tratamento 1). Por ter alcançado uma redução maior que $25 \%$ de gordura, os tratamentos (T3 e T4) podem ser considerados light, pela legislação (BRASIL, 2003). Portanto, isto significa que a adição de farinha de aveia melhora a qualidade nutricional quanto ao requisito de alimento saudável, diminuindo o teor de gordura do produto, cumprindo, assim, o objetivo do estudo.

Esses resultados corroboram com os encontrados por Almeida, 2011, que ao adicionar fibra vegetal de aveia em hambúrgueres de carne caprina, encontrou uma redução de quatro vezes o valor de lipídeo do tratamento com maior adição de farinha de aveia $(2 \%)$.

Para os valores de $\mathrm{pH}$ também houve diferença significativa $(\mathrm{P}<0,05)$. O valor do $\mathrm{pH}$ aumentou ligeiramente nos tratamentos 3 e 4 , onde foram adicionados maior percentual de farinha de aveia. Esta variação não afetou negativamente os hambúrgueres visto que permaneceram dentro da faixa de $\mathrm{pH}$ para carne vermelha que é de 6,2 a 5,4 (FORSYTHE, 2002).

De acordo com Fernandes e Pizato (2019), o aumento da concentração adição de farinha de sorgo em hambúrguer, fez com que aumentassem os valores de pH. Já Trevisan et al., (2016) adicionando 3 e $6 \%$ de fibra de aveia em hambúrgueres bovino, observaram valor mais baixo de $\mathrm{pH}$, quando a concentração da fibra era maior.

Sabe-se que o abaixamento do $\mathrm{pH}$ pode afetar a capacidade emulsificante das proteínas miofibrilares. Além do efeito tecnológico, o $\mathrm{pH}$ também influencia o desenvolvimento microbiano e reações químicas e físicas que acarretam a deterioração do produto. Por isso, o manuseio em boas condições sanitárias, a estocagem à baixa temperatura e o sistema de embalagem são elementos chaves na manutenção do pH e consequentemente no aumento da vida de prateleira do produto (JIMÉNEZCOLMENERO, 2007; FORSYTHE, 2002).

Ao avaliar os resultados da Tabela 02, pode-se observar que à medida que aumentou-se a concentrações de farinha de aveia e reduziu-se a concentração de gordura utilizada, a atividade de água dos hambúrgueres aumentou $(\mathrm{p}<0,05)$. Isso ocorreu possivelmente pelo fato de a farinha de aveia apresentar alta higroscopicidade, enquanto a gordura é hidrofóbica. 
INÔ, et al.

Substituindo o toucinho em hambúrgueres de frango, com adição de semente de chia (0, 2, 4 e 8\%) Paula et al., (2019) não perceberam diferença significativa entre os tratamentos para os valores de atividade de água (Aw). O mesmo não foi observado por Boechat et. al., (2016), que substituíram toucinho suíno de hambúrgueres bovinos por biomassa e farinha de banana, obtendo valores de Aw variando de 0,948 a 0,953.

Enquanto MELO et al., (2013) ao desenvolverem hambúrgueres de carne bovina com substituição da gordura animal por farinha desengordurada de gergelim, observaram redução nos valores de atividade de água à medida que aumentava a proporção de farinha.

Conforme pode ser observado na Tabela 03, os maiores rendimentos foram obtidos pelos Tratamentos (T2, T3 eT4), indicando que a adição do farinha de aveia em substituição à gordura, nos níveis utilizados no presente trabalho, pode contribuir com aumento da massa do hambúrguer devido a presença das fibras e amido na farinha que proporcionam volume à massa e textura ao produto. $\mathrm{O}$ rendimento de hambúrguer é de grande valia, pois, repercute na quantidade do produto após a cocção.

Dentre as vantagens da utilização de fibra de aveia em produtos cárneos como substituto de gordura, destaca-se sua alta capacidade de retenção de água que auxilia no aumento do rendimento do produto final (TALUKDER, 2015). O aumento na porcentagem de fibra de aveia solúvel ( $\beta$-Glucana), adicionada em um produto cárneo cozido com redução de gordura, aumentou significativamente o rendimento (PIÑERO et al., 2008; ÁLVAREZ; BARBUT, 2013).

Tabela 03. Média ( \pm desvio padrão) dos parâmetros físicos dos hambúrgueres.

\begin{tabular}{ccccc}
\hline \multirow{2}{*}{ Caracterizaçãa do Cozimento } & \multicolumn{4}{c}{ Tratamentos \% } \\
\cline { 2 - 5 } & T1 & T2 & T3 & T4 \\
\hline \hline Rendimento de Cocção & $70,61 \pm 1,81^{\text {a }}$ & $80,51 \pm 0,37^{\mathrm{b}}$ & $86,36 \pm 1,29^{\mathrm{c}}$ & $88,33 \pm 1,11^{\mathrm{d}}$ \\
Perda de Peso por Cocção & $26,3 \pm 1,41^{\mathrm{a}}$ & $18,39 \pm 1,03^{\mathrm{b}}$ & $12,63 \pm 1,25^{\mathrm{c}}$ & $10,8 \pm 0,78^{\mathrm{d}}$ \\
Porcentagem de Encolhimento & $20,32 \pm 1,64^{\mathrm{a}}$ & $14,16 \pm 0,83^{\mathrm{b}}$ & $5,3 \pm 1,88^{\mathrm{c}}$ & $2,27 \pm 0,72^{\mathrm{d}}$ \\
\hline T1(0,0\% farinha de aveia, 17,4\% de gordura suína); T2 (4,4\% farinha de aveia, 13,0\% gordura suína); \\
T3(8,7\% farinha de aveia, 8,7\% gordura suína) e T4 (13,0\% farinha de aveia, 4,4\% gordura suína). * (RC) \\
Rendimento de Cocção; (PPC) Perda de Peso por Cocção e (PE) Porcentagem de Encolhimento. Médias \\
seguidas de letras diferentes na mesma linha diferem (p<0,05) entre si pelo teste F.
\end{tabular}

Fonte: Própria (2020).

De acordo com Oliveira et al., (2014), foi observado que quanto maior a quantidade de farinha de linhaça dourada adicionada, maior foi o rendimento, bem como a retenção de água após processo de cocção, contribuindo ainda para o menor encolhimento dos hambúrgueres desenvolvidos. 
Machado (2014) ao desenvolver e avaliar a qualidade nutricional de um produto cárneo tipo hambúrguer com substituição parcial da gordura suína por farinha de quinoa, relatou valores de rendimento entre 70 e $84,93 \%$.

Estudos realizados por Almeida (2011), em hambúrguer caprino adicionado de 4 $\%$ farinha aveia demonstraram resultados similares ao presente trabalho, sendo que o rendimento dos hambúrgueres aumentou à medida que elevou-se a concentração da farinha de aveia. Costa (2004) também verificou que a utilização de uma mistura de farelo e fibra de aveia proporcionou ao hambúrguer rendimento superior $(15,0 \%)$ ao do controle após o cozimento.

Em relação a Perda de Peso por Cocção, os valores estão diretamente relacionados com o Rendimento de Cocção, uma vez que quanto menor a perda de peso maior o rendimento de cocção, conforme pode ser observado na tabela 03 . O tratamento T4 apresentou a menor perda de peso, mostrando que a adição de $13 \%$ de farinha de aveia colaborou com esta propriedade no reaquecimento.

Alguns autores afirmam que as vantagens na utilização de fibra ou farelo de aveia incluem sua superior capacidade de reter umidade e evitar que o produto resseque durante o cozimento, além da capacidade de reter o aroma da carne (MEINHOLD, 1991; PSZCZOLA, 1991). A perda de peso em produtos cárneos pode ser associada à mudança de fase que ocorre quando o produto é submetido ao aquecimento, na qual a gordura passa do estado sólido para líquido como consequência da aplicação de calor.

O efeito contrário se observa no parâmetro encolhimento, sendo que os tratamentos com maior porcentagem de farinha de aveia presentaram um encolhimento menor $(\mathrm{p}<0,05)$ quando comparado ao tratamento controle (T1), no qual não houve adição da farinha.

No que se diz respeito à porcentagem de encolhimento, sabe-se que este é causado pela desnaturação de proteínas durante o processo de cozimento e parcialmente pela evaporação e fusão das gorduras da carne (ULU, 2006). O desempenho de cozimento também possui influência da estrutura da matriz formada no produto reestruturado. Sítios que favoreçam a saída de água ou a desnaturação de proteínas impactarão em menores percentuais de encolhimento (HUBER, 2012). Esta pode ser uma das causas da variabilidade dos resultados destes parâmetros, apresentada neste e nos trabalhos citados.

Em estudo com hambúrguer de carne bovina, Bis (2016) relata que o maior encolhimento foi observado para o tratamento com redução de gordura e sem adição de fibra de aveia, enquanto o tratamento com menor encolhimento foi com adição de $6 \%$ de 
INÔ, et al.

fibra de aveia.

Os resultados obtidos nas análises microbiológicas dos hambúrgueres crus de carne bovina se mostraram dentro dos limites estabelecidos pela legislação vigente e são apresentados na tabela 04 .

Tabela 04. Resultados microbiológicos dos hambúrgueres de carne bovina com 3 dias de estocagem sob congelamento.

\begin{tabular}{|c|c|c|}
\hline \multirow{2}{*}{ Tratamentos } & \multicolumn{2}{|c|}{ Análise microbiológica de Coliformes a $45^{\circ} \mathrm{C}$} \\
\hline & Resultado & Limite* (Padrão Microbiológico) \\
\hline $\mathrm{T} 1$ & $<1100 \mathrm{NMP} / \mathrm{g}$ & $5,0 \times 10^{3} \mathrm{NMP} / \mathrm{g}$ \\
\hline $\mathrm{T} 2$ & $<1100 \mathrm{NMP} / \mathrm{g}$ & $5,0 \times 10^{3} \mathrm{NMP} / \mathrm{g}$ \\
\hline $\mathrm{T} 3$ & $<1100 \mathrm{NMP} / \mathrm{g}$ & $5,0 \times 10^{3} \mathrm{NMP} / \mathrm{g}$ \\
\hline $\mathrm{T} 4$ & $<1100 \mathrm{NMP} / \mathrm{g}$ & $5,0 \times 10^{3} \mathrm{NMP} / \mathrm{g}$ \\
\hline
\end{tabular}

T1(0,0\% farinha de aveia, 17,4\% de gordura suína); T2 (4,4\% farinha de aveia, 13,0\% gordura suína); T3(8,7\% farinha de aveia, $8,7 \%$ gordura suína) e T4 (13,0\% farinha de aveia, 4,4\% gordura suína). *Brasil, 2001.

Fonte: Própria (2020).

Conforme observado na tabela acima, todas as amostras estão bem abaixo do máximo preconizado pela legislação vigente para Coliformes a $45^{\circ} \mathrm{C} / \mathrm{g}$ e revelam condições sanitárias satisfatórias do produto para consumo humano, podendo ser empregado na análise sensorial, de acordo com a Resolução RDC n. 12 da Agência Nacional da Vigilância Sanitária (BRASIL, 2001).

Os coliformes totais são encontrados em fezes, mas também em outros ambientes como vegetais e o solo, persistindo por tempo superior ao de bactérias patogênicas de origem intestinal, a presença desse grupo de microrganismos em alimentos não indicam, necessariamente, que a contaminação seja de origem fecal recente (FRANCO; LANDGRAF, 1996).

A Tabela 05 apresenta as médias dos valores atribuídos pelos consumidores aos tratamentos de hambúrguer bovino com adição de farinha de aveia. À medida que foi reduzido o teor de gordura e adicionado à farinha de aveia observou-se uma queda nos valores das médias obtidas das análises de cor, sabor, textura, aroma e aparência. Em geral todas as formulações foram bem aceitas pelos consumidores.

Tabela 05. Média ( \pm desvio padrão) dos atributos sensoriais dos hambúrgueres.

\begin{tabular}{cccccc}
\hline \multirow{2}{*}{ Tratamentos } & \multicolumn{5}{c}{ Atributos Sensoriais } \\
\cline { 2 - 6 } & Cor & Sabor & Textura & Aroma & Aparência \\
\hline \hline T1 & $8,33 \pm 0,80^{\mathrm{a}}$ & $8,03 \pm 1,03^{\mathrm{a}}$ & $7,83 \pm 0,94^{\mathrm{a}}$ & $7,73 \pm 1,38^{\mathrm{a}}$ & $8,10 \pm 0,80^{\mathrm{a}}$ \\
$\mathrm{T} 2$ & $7,36 \pm 1,32^{\mathrm{b}}$ & $8,00 \pm 1,31^{\mathrm{a}}$ & $7,76 \pm 1,27^{\mathrm{a}}$ & $7,66 \pm 1,32^{\mathrm{a}}$ & $8,06 \pm 0,90^{\mathrm{ab}}$
\end{tabular}


T1(0,0\% farinha de aveia, 17,4\% de gordura suína); T2 (4,4\% farinha de aveia, 13,0\% gordura suína); T3(8,7\% farinha de aveia, 8,7\% gordura suína) e T4 (13,0\% farinha de aveia, 4,4\% gordura suína). Médias seguidas de letras diferentes na mesma coluna diferem $(\mathrm{p}<0,05)$ entre si pelo teste $\mathrm{F}$.

Fonte: Própria (2020).

Observa-se que para o atributo sabor e aroma, todas as formulações foram consideradas iguais ( $p>0,05$ ), possuindo média de pontos de 7,6, e 7,5 respectivamente, o que equivale a gostei moderadamente a gostei muito na escola hedônica de 9 pontos.

Em relação a cor, houve diferença significativa $(p<0,05)$ entre o tratamento 1 (sem adição de farinha de aveia) e os demais tratamentos com adição de farinha (T2, T3 e T4). A amostra com maior média para a cor foi o tratamento controle T1 8,33 (gostei moderadamente) sem adição da farinha de aveia. A presença da fibra insolúvel, alterou a coloração dos demais tratamentos, que obtiveram média de 7 (gostei moderadamente).

Para o atributo textura também houve interação significativa $(p<0,05)$ entre as amostras, que apresentaram média na escala de 7 (gostei moderadamente) e 6 (gostei ligeiramente). A menor nota pode ser atribuída ao fato de que à medida em que se acrescenta fibra e reduz gordura, o produto tende a reduzir a sua maciez.

De modo geral, as amostras de todos os tratamentos, foram avaliadas pelos consumidores com médias entre 6 "gostei ligeiramente" e 8 "gostei muito", o que indica aceitabilidade satisfatória (DUTCOSKY, 2011).

Grande parte dos estudos realizados com substitutos de gordura em produtos cárneos também vem obtendo boa aceitação sensorial quando submetidos à avaliação com provadores (LAMAS, 2016). Teixeira et al. (2008) verificaram que em hambúrgueres de carne bovina com diferentes níveis de farinha de aveia $(0 ; 2$ e 4\%), a preferência pela amostra com $2 \%$ de farinha de aveia foi indicada por em $35 \%$ dos provadores.

Em relação ao teste de perfil de consumo de hambúrguer $(93,0 \%)$ dos provadores responderam que consomem esse produto. A maioria dos indivíduos que participaram da análise sensorial se encontrava na faixa etária entre 15 e 20 anos $(63,33 \%)$ e pertenciam ao sexo feminino (70\%). A frequência de consumo de hambúrguer foi de $(36,67 \%)$ uma vez por mês, enquanto que (30\%) consomem mais de 5 vezes ao mês.

Sobre alimentos funcionais, $(76,67 \%)$ disseram que tem conhecimento ou que já ouviram falar sobre esse assunto e $(66,67 \%)$ informaram que consomem algum tipo de alimento funcional. Quando questionados sobre a intenção de compra de hambúrguer 
INÔ, et al.

adicionado de farinha de aveia, todos os provadores foram unânimes e afirmaram que comprariam hambúrguer enriquecido com fibra.

\section{Conclusões}

A substituição do toucinho pela farinha de aveia não só resultou em um produto de menor valor calórico, mas também melhorou características tecnológicas de rendimento, encolhimento e perda de peso, além de uma boa aceitação sensorial.

Sendo assim a adição de farinha de aveia ao hambúrguer pode ser considerada uma alternativa tecnológica para produção de um produto cárneo que agregue tanto a praticidade, sabor e ao mesmo tempo a qualidade nutricional, com potencial para ser estudado, melhorado e comercializado.

\section{Referências}

ALMEIDA, R. S. Processamento de hambúrguer de carne caprina adicionados com diferentes níveis de farinha de aveia. 2011. 73p. Ilustrado. Dissertação (Programa de Pós-Graduação) -Universidade Estadual do Sudoeste da Bahia, 2011.

ÁLVAREZ, D.; BARBUT, S. Effect of inulin, $\beta$-glucan and their mixtures on emulsion stability, color and textural parameters of cooked meat batters. Meat Science, Barking, v. 94 , n. 3, p. 320-327, 2013.

ANDERSON, E. T.; BERRY, B. W. Effects of inner pea fiber on fat retention and cooking yield in hight ground beef. Food Research International, v. 1, n. 1, p. 1-7, 2001 .

AOAC. Association of Official Analytical Chemists. Official methods of analysis of AOAC International. 17th ed. Gaithersburg, 2000. v. 2.

ARISSETO, A. P.; POLLONIO, M. A. R. Avaliação da estabilidade oxidativa do hambúrguer tipo calabresa, formulado com reduzidos teores de nitrito e diferentes percentagens de gordura, durante armazenamento congelado. Revista Higiene Alimentar, v. 19, n. 136, 72-80, 2005.

BIS, C. V. Efeito das fibras alimentares como substitutos de gordura em hambúrguer de carne bovina e paio. Dissertação (Mestrado em Engenharia e Ciência de Alimentos). Universidade Estadual Paulista "Júlio de Mesquita Filho", São José do Rio Preto, SP. 2016.

BOECHAT, P.G.R.; VIDIGAL, J.D.; CRISTÓFORI, J.C.R.A.; REBELLO, L.P.G.; SILVA, C.O.; SILA, A. B. Aproveitamento integral de biomassa e farinha de banana verde na produção de hambúrguer bovino. In: XXV Congresso Brasileiro de Ciência e Tecnologia de Alimentos, 2016, . Anais eletrônicos... Gramado, RS, 2016. 
BORBA, C.M., OLIVEIRA, V. R., MONTENEGRO, K. R., HERTZ, P. F., VENZKE, J. G. Avaliação físico química de hambúrguer de carne bovina e de frango submetidos a diferentes processamento térmicos. Brazilian Journal of Food Nutrition, 24(1), 21-27. 2013.

BRASIL. Ministério da Saúde. Agência Nacional de Vigilância Sanitária, ANVISA. Resolução RDC no 359, de 23 de dezembro de 2003. Aprova Regulamento Técnico de Porções de Alimentos Embalados para Fins de Rotulagem Nutricional. Diário Oficial da União, Brasília, 2003.

BRASIL. Ministério da Saúde. Agência Nacional de Vigilância Sanitária, ANVISA. Resolução RDC n 12, de 02 de janeiro de 2001. Aprova o Regulamento Técnico sobre padrões microbiológicos para alimentos. Diário Oficial da União; Poder Executivo, 10 jan., 2001.

BRASIL. Ministério da Agricultura e do Abastecimento. Secretaria de Defesa Agropecuária/Órgão: DIPOA - Departamento de Inspeção de Produtos de Origem Animal. Regulamento técnico de identidade e qualidade de hambúrguer, anexo IV. Diário Oficial da União, Brasília, DF, 3 de agosto de 2000.

CARVALHO, L. T. Parâmetros tecnológicos, aceitação sensorial e sensação de saciedade após consumo de hambúrguer bovino com adição de fibra de trigo e teor de gordura reduzido. Dissertação (Mestrado em Ciências). Universidade de São Paulo, Pirassununga, SP. 2015.

CARBONELL, L. A. et al. Functional and sensory effects of fibre-rich ingredients on breakfast fresh sausages manufacture. Food Science and Technology International. v. 11(2), 2005, p. 89-97.

CIRIANO, M. G. I.; BERASATEGI, I.; NAVARRO-BLASCO, I.; ASTIASARAN, I.; ANSORENA, D. Reduction of sodium and increment of calcium and omega3 polyunsaturated fatty acids in dry fermented sausages: effects on the mineral content, lipid profile and sensory quality. Journal of the Science of Food and Agriculture, v. 93, n. 4, p. 876-881, 2013.

COLMENERO, F.J. CARBALLO, J. COFRADES, S. Healthier meat and meat products: their role as functional foods. Meat Science, v. 59, ed. 1. P. 5-13, set 2001.

COSTA, L.O. Processamento e Diminuição do Reprocesso do Hambúrguer Bovino (HBV). 2004. 127f. Trabalho de Conclusão de Curso (Graduação em Engenharia de Alimentos) - Universidade Católica de Goiás, Goiânia, 2004.

DA SILVA, NRF; FERNANDES, EL; SILVEIRA, TC; ESCUDINI, SV; VIDIGAL, JG; KAWASE, KYF; BORGES, JTS.. Aceitação de hambúrguer formulado com substituição de gordura animal por farinha de semente de chia. Hortic. bras, v. 31, n. 2. (Suplemento-CD Rom), julho 2014.

DUTCOSKY, S. D. Análise sensorial de alimentos. 3.ed. Curitiba: Champagnat, 2011. p. 423. 
FERNANDES, A.B.C., PIZATO, S. Elaboração de hambúrguer de carne bovina com adição de farinha de sorgo (Sorghum Vulgare). PubSaúde, 2, 2019.

FORSYTHE, S.J. Microbiologia de segurança alimentar. Tradução de: Maria Carolina Minardi Guimarães e Cristina Leonhardt. Porto Alegre: Artmed, 2002, p. 1-42.

GONÇÁLVES, M. S.; SILVA, B.M. T.; PALHARES, P. C.; NEVES. M. P.; SILVA, V. R.; RAMOS, E. M. Elaboração e análise físico-químicas de hambúrguer adicionado de chia e transglutaminase. XXV Congresso Brasileiro de Ciência e Tecnologia de Alimentos. 24 a 27 de outubro de 2016 - FAURGS - Gramado / RS.

HUBER, E. Desenvolvimento de produtos cárneos reestruturados de frango (hambúrguer e empanado) com adição de fibras vegetais como substitutos totais de gordura. Tese (Doutorado em Engenharia de Alimentos). Universidade Federal de Santa Catarina. Florianópolis, 2012.

JIMÉNEZ-COLMENERO, F. Healthier lipid formulation approaches in meat based functional foods. Technological options for replacement of meat fats by non-meat fats. Trends Food Science Technology, v.18, n.11, p.567-578, 2007.

JUNIOR, Walter José dos Reis. Utilização de farinha da casca do abacaxi (Ananas comosus (l.) Merr.) para desenvolvimento de hambúrguer bovino com teor reduzido de gordura. 2017. 67p Dissertação (Mestrado em Ciência e Tecnologia de Alimentos). Instituto de Tecnologia, Departamento de Tecnologia de Alimentos, Universidade Federal Rural do Rio de Janeiro, Seropédica, RJ, 2017.

LAMAS, Karoliny de Oliveira, Mestrado Profissional, Instituto Federal de Educação, Ciência e Tecnologia do Sudeste de Minas Gerais, março de 2016. Utilização de farinha de chia (Salvia hispanica L.) como substituta parcial de gordura na elaboração de hambúrguer de frango. Rio Pomba-MG,78f., 2016.

LÓPEZ-VARGAS, J. H. et al. Quality characteristics of pork burger added with albedo-fiber powder obtained from yellow passion fruit (Passiflora edulis var. flavicarpa) co-products. Meat Science, v. 97, n. 2, p. 270-276, jun. 2014.

\section{MACHADO, E. A. Avaliação da Qualidade Nutricional de Hamburgueres}

Suplementados com farinha de quinoa: 2014. 40 f. Trabalho de Conclusão de Curso (Graduação do curso superior em tecnologia em Alimentos) - Universidade Tecnológica Federal do Paraná. Francisco Beltrão, 2014.

MARQUES, J. M. Elaboração de um Produto de Carne Bovina "Tipo Hambúrguer" Adicionado de Farinha de Aveia. 2007. 71f. Dissertação (Mestrado em Tecnologia de Alimentos) - Universidade Federal do Paraná, Curitiba, 2007.

MEINHOLD, N. M. Processed meats with 38-75\% less fat. Food Processing, v.52, n.1, p. 105-106, 1991.

MELO, L.S.M.; CLERICI, M.T.P.S. Desenvolvimento e avaliação tecnológica, sensorial e físicoquímica de produto cárneo, tipo hambúrguer, com substituição de gordura por farinha desengordurada de gergelim. Alim Nutr. = Braz J Food Nutr., 
Out-Dez; 24(4): 361-368. 2013.

MONEGO, Magda Aita. Goma da linhaça (linum usitatissimum 1.) para uso como hidrocolóide na indústria alimentícia. 2009. Dissertação (Mestrado em Ciência e Tecnologia de Alimentos) - Universidade Federal de Santa Maria, Santa Maria - RS. 2009.

OLIVEIRA, D. F. et al. Farinha de linhaça dourada como substituto de gordura animal em hambúrguer de carne bovina com redução de sódio. Brazilian Journal of Food Technology Campinas, v. 17, n. 4, p. 273-282, out./dez. 2014.

PAULA, M. M. D.O. et al. Technological and sensory characteristics of hamburgers added with chia seed as fat replacer. Ciência Rural, v. 49, n. 8, 2019.

PIÑERO, M. P.; PARRA, K.; HUERTA-LEIDENZ, N.; ARENAS DE MORENO, L.; FERRER, M.; ARAUJO, S.; BARBOZA, Y. Effect of oat's soluble fibre (beta-glucan) as a fat replacer on physical, chemical, microbiological and sensory properties of lowfat beef patties. Meat Science, Barking, v. 80, n. 3, p. 675-680, 2008.

PSZCZOLA, D. E. Oat-bran based ingredient blend replaces fat in ground beef and pork sausage. Food Technology, v. 45, n.60, p. 60-66, 1991.

QUEIROZ, Y. U. et al. Desenvolvimento e avaliação das propriedades físico-químicas de hambúrgueres com reduzidos teores de gordura e de colesterol. Revista Nacional da Carne. ed. 338. Abril, 2005.

SEABRA, L. M. J. et al. Fécula de mandioca e farinha de aveia como substitutos de gordura na formulação de hambúrguer de carne ovina. Ciência e Tecnologia de Alimentos, Campinas, v. 22, n.3, set./dez. 2002.

SILVA, Carlos Eduardo da.; et al. Influência de diferentes métodos de cocção sobre os macro e micronutrientes de hambúrguer bovino com linhaça. Rev. Nutr. clín. diet. hosp. 38(3):111-119.2018.

SILVA, N.; JUNQUEIRA, V. C. A.; SILVEIRA, N. F. A. Manual de métodos de análise microbiológica de alimentos. 2. ed. São Paulo: Varela, 2001. 317 p.

TALUKDER, S. Effect of dietary fiber on properties and acceptance of meat products: a review. Critical Reviews in Food Science and Nutrition, Cleveland, v. 55, n. 7, p. 1005-1011, 2015.

TEIXEIRA, T. R. M.; PERIN, C. P.; FREITAS, M. S.; JARDIM, F. B. B. Avaliação sensorial e do rendimento de hambúrgueres bovinos enriquecidos com aveia. In:

Jornada Científica das Faculdades Associadas de Uberaba. Uberaba, p.13-17, 2008.

TERRA, N. N. Apontamentos de tecnologia de carnes. São Leopoldo: UNISINOS, $1998.216 \mathrm{p}$.

TERRA, N. N.; BRUM, M. A. R. Carne e seus derivados: técnicas de controle de qualidade. São Paulo: Nobel, 1988. 119 p. 
INÔ, et al.

TREVISAN, Y. C., et al. Efeito da adição de fibra de aveia sobre as propriedades físicoquímicas de hambúrguer cozido e congelado com redução de gordura e sal. Brazilian Journal of Food Technology, v.19, e2015079, 2016.

ULU, H. Effects of carrageenam and guar on the coking and textural properties of low fat meatballs. Food Chemistry, v.95, n.4, p.600-605, 2006.

VALENTE, T. P.; DE MESQUITA, M. O.; MANFIO, M. Produto cárneo acrescido de fibra com baixo teor de sódio. Disciplinarum Scientia. Série: Ciências da Saúde, Santa Maria, v. 15, n. 1, p. 91-100, 2014. 